\title{
Células-tronco mononucleares autólogas e proteína óssea morfogenética na cicatrização de defeitos tibiais experimentalmente induzidos em cães
}

[Autologue mononuclear stem cells and morphogenetic bone protein in experimentally induced tibial defect healing in dogs]

G.K. Oliveira ${ }^{1}$, A.G. Raiser ${ }^{2}$, D. Olsson ${ }^{1}$, F.Z. Salbego ${ }^{1}$, D.B. Martins ${ }^{1}$, R. Dezengrine ${ }^{1}$, E.B. Santos Júnior ${ }^{1}$, J. Rappeti ${ }^{1}$, L.B. Trindade ${ }^{1}$, G.K. Tognoli ${ }^{1}$, N.L. Pippi ${ }^{2}$, L. Sausen ${ }^{3}$

\author{
${ }^{1}$ Aluno de pós-graduação - UFSM - Santa Maria, RS \\ ${ }^{2}$ Centro de Ciências Rurais - UFSM - Santa Maria, RS \\ ${ }^{3}$ Aluno de graduação - UFSM - Santa Maria, RS
}

\begin{abstract}
RESUMO
Avaliou-se a utilização de células-tronco mononucleares (CTM) na cicatrização de defeito ósseo experimental como alternativa aos métodos convencionais, analisando-se o tempo de evolução cicatricial e a presença dessas células no tecido neoformado. Foram utilizados 18 cães, separados em três grupos $(\mathrm{G})$ de seis, e de cada animal foram colhidas células da medula óssea (MO), contadas e analisadas para morfometria, por meio da contagem manual e mielograma. Um defeito ósseo tibial foi então criado cirurgicamente, e a lesão tratada com esponja de gelatina embebida em solução fisiológica (G1), esponja de gelatina embebida com aspirado de MO processado (G2) e esponja de gelatina embebida com aspirado de MO processado e proteína óssea morfogenética (rhBMP-2) (G3). A cicatrização foi então avaliada por estudos radiográficos, e a presença de CTM foi identificada por meio de marcadores nanocristais Qtracker, em microscopia com luz fluorescente, uma semana após a intervenção cirúrgica. Entre as células identificadas pelo marcador, foram encontradas células da linhagem óssea. As avaliações radiográficas demonstram crescimento ósseo acelerado nos animais de G2 e G3. Houve diferenças significativas entre o G1 e G3 em todos os tempos estudados, e entre G1 e G2 nos tempos de 30 e 45 dias. A utilização de CTM adultas suplementadas ou não com rhBMP-2 é alternativa favorável ao crescimento ósseo em defeitos experimentais agudos de tíbia de cães.
\end{abstract}

Palavras-chave: cão, células-tronco, rhBMP-2, tíbia

\begin{abstract}
Mononuclear stem cells (MSC) were experimentally implanted in bone defect, as an alternative to the conventional methods, in order to evaluate the healing speed, and the presence of these cells in the newborn tissue. Bone marrow (BM) was collected from $18 \mathrm{dogs}$, and then counted and morphometrically analyzed by manual count and myelogram. The dogs were separated in three groups $(G)$ of six animals each. A tibial bone defect was surgically made in each dog and the wound was treated with gelatin sponge and physiologic solution (G1), gelatin sponge and processed BM (G2), and gelatin sponge, processed BM, and rhBMP-2 (G3). The healing was evaluated by radiographic study and the presence of MSC was microscopically identified by Qtracker nanocrystal labeler with a fluorescent light one week after the surgery. Cells from the bone lineage were found among the labeled cells. The radiographic evaluations demonstrated a speed up in bone growth in dogs from $G 2$ and G3, and significant differences were found between $G 1$ and G3 dogs, in all studied periods; and between G1 and G2 animals at 30 and 45 days. The rhBMP-2 supplemented or not-supplemented adult MSC are favorable alternatives to the bone growth in the healing process of acute experimental-induced tibial defects in dogs.
\end{abstract}

Keywords: dog, stem cells, rhBMP-2, tibial

Recebido em 31 de julho de 2009

Aceito em 9 de fevereiro de 2010

E-mail: grakopinits@yahoo.com.br 


\section{INTRODUÇÃO}

Terapias alternativas, que auxiliem na recuperação de fraturas, são muito importantes, pois podem minimizar o tempo de tratamento e os custos, e garantir o retorno mais rápido às atividades normais (Douat, 2004).

Sabe-se que vários tipos celulares estão em investigação em experimentos com animais, porém o maior potencial terapêutico está nas células-tronco (CT). A CT é um tipo especial de célula com capacidade de proliferação indefinida, autorrenovação, produção de diferentes linhagens celulares e regeneração de tecidos. Está presente principalmente em embriões, no cordão umbilical e na medula óssea (Silveira et al., 2005).

Modelos experimentais de defeitos ósseos tratados com CT mononucleares (CTM) têm demonstrado que ambientes biológicos e mecânicos favoráveis resultam em proliferação e diferenciação de CTM em osteoblastos e condrócitos, e que a presença de células-tronco em defeitos ósseos experimentais diminui o tempo de cicatrização do defeito (Kraus e Kirker-Head, 2006).

A presença de material de suporte é indispensável quando se necessita reconstituir tecido ósseo adulto. As especificações ideais desse scaffold são contraditórias, porém, geralmente, considera-se que este deva ser biocompatível, osteocondutor, resistente, reabsorvível, poroso, radiotransparente e maleável (Potier e Petite, 2005).

Células-tronco são identificadas principalmente por meio de marcadores de superfície (Kirschstein, 2001). Ferramentas novas de diagnóstico celular incluem pontos quânticos (QDs), que são nanocristais semicondutores caracterizados por alta fotoestabilidade e excitação de um único comprimento de onda (Azzazy et al., 2006). Segundo Garon et al. (2007), nanocristais fluorescentes podem ser localizados por pelo menos quatro gerações celulares, e algumas células permanecem marcadas por até duas semanas.

Fatores de crescimento influenciam a quimiotaxia, diferenciação, proliferação e atividade sintética de células ósseas; dessa forma, regulam fisiologicamente 0 remodelamento e a cicatrização da fratura (Sarkar et al., 2006). A proteína óssea morfogenética (rhBMP-2) é comprovadamente uma substância osteoindutora, segundo Gonçalves e Guimarães (1998), Kraus e KirkerHead (2006), Roostaeian et al. (2006), Singhatanadgit et al. (2006), Chu et al. (2007) e Ferrigno et al. (2007).

Os objetivos deste trabalho foram avaliar a atuação das CTM, suplementadas ou não com rhBMP-2, na velocidade cicatricial da tíbia de cães, e verificar a presença de CTM marcadas com nanocristais Q-tracker.

\section{MATERIAL E MÉTODOS}

Este estudo foi submetido à aprovação do Comitê em Ética em Pesquisa, com animais da Universidade Federal de Santa Maria, sob o número 23081.017095/2006-47 e seguiu os princípios éticos do Colégio Brasileiro de Experimentação Animal.

Foram utilizados 18 cães adultos, hígidos, machos ou fêmeas, com peso em torno de $8,5 \mathrm{~kg}$ (5 a 12kg), nos quais foi criado, na região medial proximal da tíbia, um defeito monocortical. Os animais foram separados em três grupos $(G)$ de seis, em que o defeito foi preenchido com esponja de colágeno (Gelfoan, Pharmacia Brasil - São Paulo). À esponja foi adicionada solução salina $0,9 \%(\mathrm{G} 1)$, medula óssea (MO) processada (G2) ou MO processada e rhBMP-2 (G3).

A medicação pré-anestésica (MPA) foi realizada com maleato de acepromazina $\left(0,05 \mathrm{mg} \mathrm{kg}^{-1}\right)$, e cloridrato de fentanila $\left(0,002 \mathrm{mg} \mathrm{kg}^{-1}\right)$, por via intramuscular. Além disso, realizou-se anestesia local epidural, com lidocaína $2 \%\left(0,125 \mathrm{~mL} \mathrm{~kg}^{-1}\right)$, bupivacaína (mesma dose) e morfina $\left(0,1 \mathrm{mg} \mathrm{kg}^{-}\right.$ $\left.{ }^{1}\right)$. Após, foi feita a indução anestésica com propofol $\left(6 \mathrm{mg} \mathrm{kg}^{-1}\right)$, intubação orotraqueal e manutenção anestésica com halotano vaporizado em oxigênio.

A fluidoterapia intravenosa durante todo o procedimento foi realizada com solução de Ringer com lactato, e como profilaxia antimicrobiana administrou-se cefalotina $(30 \mathrm{mg}$ $\mathrm{kg}^{-1}$ ), por via intravenosa, 10 minutos antes do procedimento cirúrgico. 
Após antissepsia e colocação de panos de campo, os animais foram posicionados em decúbito lateral direito e submetidos à colheita de $10 \mathrm{~mL}$ $\mathrm{kg}^{-1}$ sangue da MO, da crista ilíaca e da fossa trocantérica femoral, em seringas de $20 \mathrm{~mL}$, heparinizadas. A medula foi colhida e transferida para a bolsa de colheita de MO, Kit Bone Marrow, contendo $0,1 \mathrm{~mL}$ de heparina e $10 \mathrm{~mL}$ de solução salina $0,9 \%$ para cada $100 \mathrm{~mL}$ de MO. O total de sangue intramedular colhido foi filtrado pelo Kit Bone Marrow pré-filtro de $500 \mu$ e filtro de $200 \mu$ em linha, que foi acoplado na bolsa para filtragem das espículas ósseas. O total da amostra foi transferido para uma bolsa de transporte de MO acoplada no mesmo Kit.

No momento da colheita, uma alíquota de $3 \mathrm{~mL}$ de MO foi obtida da bolsa de infusão e usada para contagem manual da porcentagem de células nucleadas e teste de viabilidade celular com azul de Trypan em lâmina de microscopia, sendo considerada aceitável uma viabilidade acima de $70 \%$. Uma outra fração de $0,5 \mathrm{~mL}$ foi usada para confeccionar esfregaços em lâminas microscópicas para mielograma (osteomielograma) e análise morfológica das células progenitoras da MO.

A MO colhida foi centrifugada a 1800 rotações por minuto em tubos Falcon de $50 \mathrm{~mL}$ e isolada em gradiente de densidade Histopaque ${ }^{\circledR}$ 1.077, de acordo com a técnica de Boyum (1968). A nuvem de células mononucleares foi colhida por pipeta automática, colocadas em tubo Falcon de $50 \mathrm{~mL}$ para ser lavada em solução salina $0,9 \%$ e Dulbecco minimal essential médium (DMEM) com glicose a 2\%, estéril por meio de centrifugação. Após a primeira lavagem, as células mononucleares depositadas no fundo do tubo foram colhidas e passaram por uma segunda lavagem, obtendo como produto final o botão celular padronizado em $500 \mu \mathrm{L}$. Uma pequena alíquota $(20 \mu \mathrm{L})$ da fração total de células mononucleares (FTCM) suspensas foi colhida com pipeta automática para contagem manual da porcentagem (quantificação) de células mononucleares e teste de viabilidade celular com azul de Trypan 1\% em câmara de Neubauer, sendo considerada aceitável uma viabilidade acima de $70 \%$.

Também uma fração $(10 \mu \mathrm{L})$ de FTCM do botão celular foi resgatada para esfregaço e posterior quantificação de células mononucleares ideais para serem injetadas. $\mathrm{O}$ restante do botão $(470 \mu \mathrm{L})$ com FTCM foi diluído em $3 \mathrm{~mL}$ de solução salina para transplante. As células a serem transplantadas (botão celular) foram marcadas por nanocristais fluorescentes (Fig. 1A). No grupo G3, após formar o botão celular, foi incubada uma alíquota de $50 \mathrm{ng} \mathrm{mL}^{-1}$ de rhBMP-2.

Após o processamento das CTM, no mesmo dia da coleta, em cada animal, mediante abordagem medial da tíbia, sob constante irrigação, foi criado um defeito monocortical de $1,5 \times 1,0 \mathrm{~cm}$ com auxílio de uma broca de desgaste sobre a região medial proximal. $\mathrm{O}$ defeito, uma vez preparado, foi preenchido com esponjas de colágeno embebidas com diferentes componentes na dependência do grupo. $\mathrm{O}$ acesso cirúrgico foi reparado por síntese da fáscia crural e do tecido subcutâneo, com fio mononáilon 3-0 e a pele com mononáilon 4-0.

No pós-operatório, administrou-se meloxican como anti-inflamatório, via intramuscular, na dose de $0,2 \mathrm{mg} \mathrm{kg}^{-1}$, uma vez ao dia, durante sete dias. $\mathrm{O}$ membro no qual foi realizado o defeito foi mantido com bandagem de Robert-Jones durante sete dias, e cada cão foi mantido em um box. Após sete dias, os pontos da pele foram removidos.

$\mathrm{Na}$ tentativa de identificar as células previamente marcadas, uma semana após a infusão do botão celular, foi realizada biopsia, em três animais de cada grupo, que consistiu em raspagem do osso, com lâmina de bisturi n. 10, nas adjacências do defeito, e confecção de lâminas para leitura em microscópio fluorescente e em microscópio óptico. Para cada animal, foram confeccionadas três lâminas para cada avaliação.

Exames radiográficos foram realizados imediatamente após a cirurgia e aos 15, 30 e 45 dias de evolução. Em cada exame foram realizadas sempre duas incidências ortogonais do membro operado para uma melhor visualização da evolução do calo ósseo. Para comparação de médias, usou-se o teste $\mathrm{t}$ por meio do programa SPSS, comparando-se a média de crescimento ósseo nos grupos aos 15, 30 e 45 dias, adotandose o nível de significância $(\mathrm{P})$ de 0,95 , no qual $\mathrm{t}$ deveria ser maior que 1,812 para ser significativo. Ao término do experimento, todos os animais foram doados. 


\section{RESULTADOS E DISCUSSÃO}

O apoio dos membros pélvicos ocorreu nas primeiras 24 horas de pós-operatório e, posteriormente, não foi observada qualquer complicação referente à locomoção. As feridas cirúrgicas cicatrizaram sem complicações. A bandagem de Robert-Jones e a caminhada com coleira foram adotadas para prevenir a ocorrência de fratura tibial na área do defeito, fato que se constatou na padronização do modelo experimental na fase pré-experimental.

O modelo experimental utilizado demonstrou ser satisfatório para avaliar a cicatrização óssea sob influência de adjuvantes, uma vez que a ausência de fixadores e materiais metálicos não influenciou na cicatrização. Segundo Prado et al. (2006), o reparo de defeitos preparados sem necessidade de osteossíntese é um bom modelo para o estudo da regeneração do osso e possui grande semelhança com o reparo primário ou direto de fraturas. Ao contrário destas últimas, os defeitos são menos sujeitos a fatores mecânicos e a obstruções do aporte sanguíneo.

O tempo de colheita de medula óssea variou de 10 minutos a uma hora e meia, sendo que, em dias mais frios, houve maior dificuldade de colheita. Isso, provavelmente, deve-se ao fato de o frio tornar o sangue mais viscoso, pois algumas amostras de medula coagularam, mesmo na presença de heparina, segundos após a colheita em dias extremamente frios. A quantidade de medula óssea colhida, $10 \mathrm{~mL} \mathrm{~kg}^{-1}$ por animal, foi estabelecida com base na pesquisa de Pizzo e Popplack (2005), em humanos, ao informar que esta é a quantidade de medula ideal a ser colhida para que um número adequado de CTM seja alcançado.

As amostras analisadas para identificação de células-tronco por meio de nanocristais Q-tracker (Tab. 1) do grupo-controle não apresentaram fluorescência quando examinadas por meio do microscópio fluorescente. No G2, das nove lâminas confeccionadas, todas apresentaram fluorescência, e no G3, das nove lâminas lidas, três apresentaram-se positivas (Fig. 1B). Ao microscópio óptico, as principais células identificadas foram osteoblastos, osteoclastos, osteócitos e hemácias (Fig. 1C e D). Dessa forma, foi possível observar que o tempo escolhido (sete dias) para realização da biopsia foi adequado, uma vez que as células não perderam a fluorescência, e, além disso, foram encontradas células marcadas que eram da linhagem óssea. Esses dados levam a supor que as células marcadas se transformaram em um dos tipos celulares encontrados na lâmina lida ao microscópio óptico e que nanocristais fluorescentes Q-tracker são marcadores úteis na identificação de células-tronco mononucleares em tecido ósseo.

Tabela 1. Resultados da avaliação por imunofluorescência e da biopsia óssea em cães para identificação das células marcadas com nanocristais Q-tracker

\begin{tabular}{ccc}
\hline \multirow{2}{*}{ Animal } & \multicolumn{2}{c}{ Amostra } \\
\cline { 2 - 3 } & Botão de células & $\begin{array}{c}\text { Fragmento } \\
\text { de osso }\end{array}$ \\
\hline 7 & ++ & ++ \\
8 & ${ }^{*}$ & $\mathrm{~N}$ \\
9 & - & $\mathrm{N}$ \\
10 & + & ++ \\
11 & + & + \\
12 & ++ & $\mathrm{N}$ \\
13 & $+++*$ & $\mathrm{~N}$ \\
14 & + & $\mathrm{N}$ \\
15 & ++ & - \\
16 & + & - \\
17 & + & + \\
18 & ++ & $\mathrm{N}$
\end{tabular}

* -: não foram encontradas células fluorescentes. ** +: raras células positivas (inferior a $5 \%$ do total); ++ número médio de células positivas (aprox. 10-20\%); +++: grande número de células fluorescentes (aprox. 30-50\%).

A dose de rhBMP-2 utilizada (50ng $\mathrm{mL}^{-1}$ ) mostrou-se adequada, uma vez que o crescimento ósseo nos grupos suplementados com esta proteína mostrou-se o melhor aos $15 \mathrm{e}$ aos 30 dias e $50 \%$ dos cães já apresentavam cicatrização completa do defeito aos 45 dias. A dose utilizada foi escolhida com base no trabalho de Roostaeian et al. (2006), os quais verificaram que a máxima resposta de atividade de fosfatase alcalina em células-tronco estromais cultivadas em presença de rhBMP-2 foi obtida quando utilizaram a dose de $50 \mathrm{ng} \mathrm{mL}^{-1}$. A vantagem de se utilizar células não expandidas, segundo Lucarelli et al. (2004), é que esse tipo de procedimento, além de ter menor custo, é mais 


\section{Oliveira et al.}

facilmente realizável, requer menor tempo de espera e menos instrumentação, e não requer imunossupressão, uma vez que o doador é o receptor e sofre mínima invasão.

Em relação à avaliação radiográfica, na Tab. 2 mostra-se a taxa de crescimento ósseo comparado ao exame radiográfico pós-operatório imediato, em cada grupo distinto (Fig. 2 A, B, C, D, E, F, G, H, I, J, K e L).
O resultado da análise estatística encontra-se na Tab. 3 e demonstrou diferenças significativas entre G1 e G3 em todos os tempos estudados, e entre $\mathrm{G} 1$ e G2, aos 30 e 45 dias. Estes resultados são favoráveis à utilização de CTM ou de CTM associadas à BMP-2 em relação ao grupocontrole. Entre G2 e G3, só aos 15 dias observaram-se diferenças significativas, o que demonstra que os dois tratamentos trazem bons resultados em defeitos ósseos experimentais de tíbia de cães.
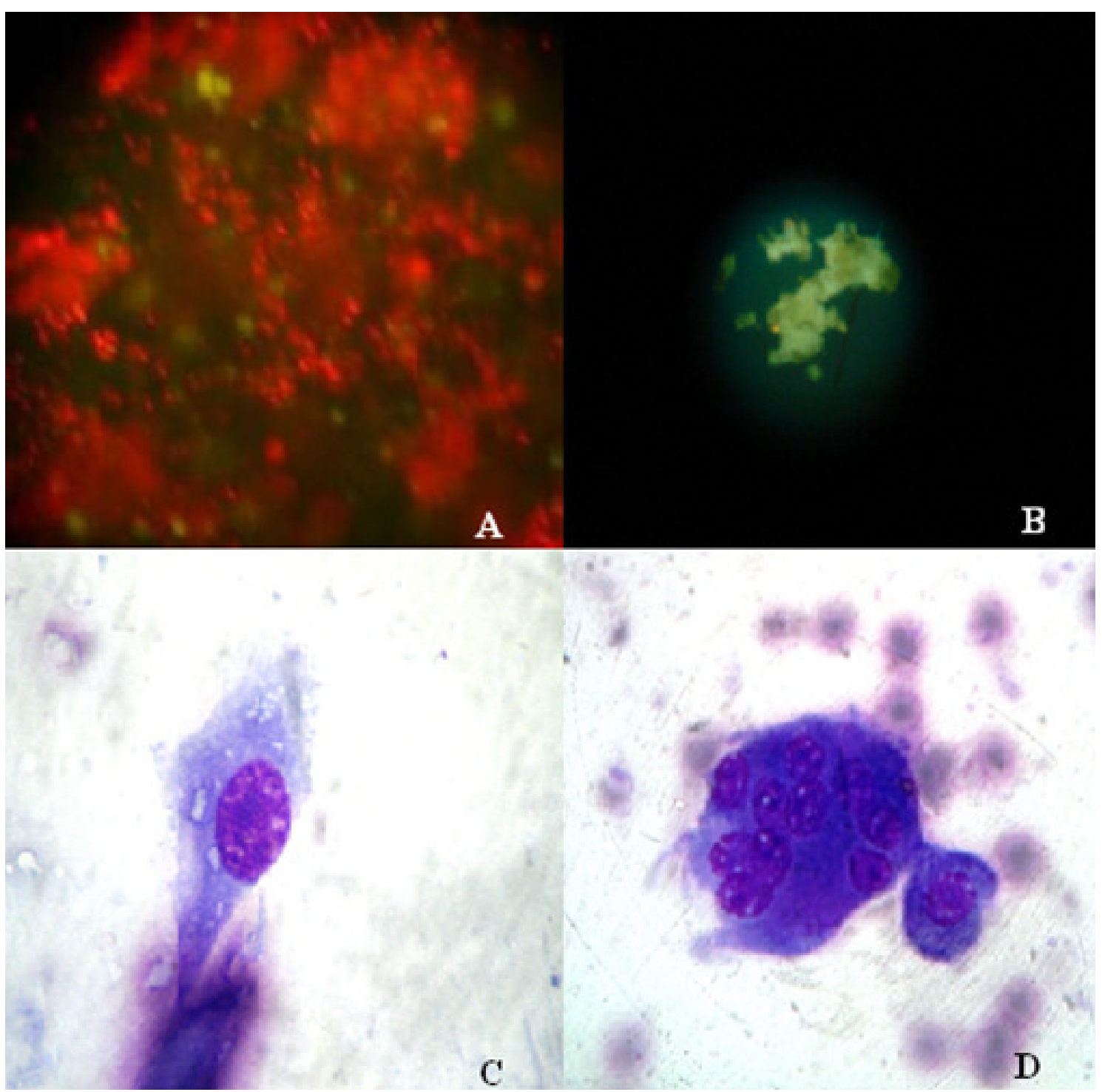

Figura 1. A: Células mononucleares marcadas com nanocristais Q-tracker, vista por meio de microscopia fluorescente (objetiva 40X) antes da inoculação. B: Tecido ósseo colhido por meio de biopsia, positivo (verdes) à leitura de microscópio fluorescente (objetiva 40X), tecido ósseo colhido por meio de biopsia à leitura do microscópio óptico. C: Osteoclastos. D: Osteócito. Objetiva 100x. 


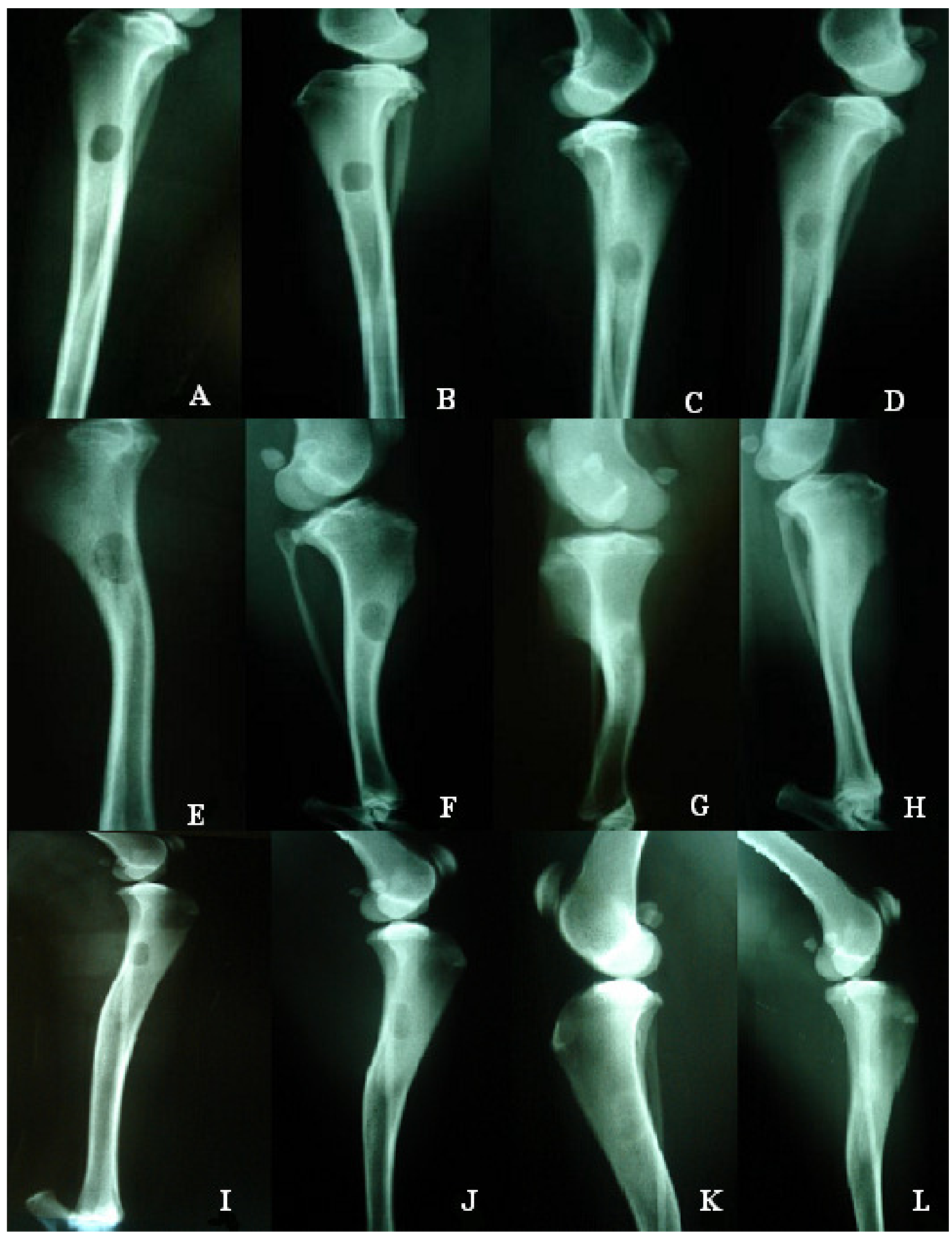

Figura 2. Sequência radiográfica que evidencia o aumento da densidade óssea nos diferentes tempos avaliados em um cão do G1 (controle): A- pós-operatório, B- 15 dias, C- 30 dias, D- 45 dias; G2 (defeito ósseo tratado com células-tronco - CTM): E- pós-operatório, F- 15 dias, G- 30 dias, H- 45 dias; G3 (CTM + proteína óssea morfogenética - rhBMP-2): I- pós-operatório, J- 15 dias, K- 30 dias, L- 45 dias. 


\section{Oliveira et al.}

Tabela 2. Taxa de crescimento ósseo, observada por meio de radiografias, segundo o tempo e o exame radiográfico pós-operatório imediato

\begin{tabular}{lllll}
\hline Animal & Grupo & 15 dias & 30 dias & 45 dias \\
\hline 1 & G1 & $10 \%$ & $40 \%$ & $60 \%$ \\
2 & G1 & $60 \%$ & $90 \%$ & $100 \%$ \\
3 & G1 & $10 \%$ & $60 \%$ & $80 \%$ \\
4 & G1 & $20 \%$ & $60 \%$ & $80 \%$ \\
5 & G1 & $10 \%$ & $40 \%$ & $70 \%$ \\
6 & G1 & $10 \%$ & $60 \%$ & $80 \%$ \\
7 & G2 & $30 \%$ & $90 \%$ & $100 \%$ \\
8 & G2 & $30 \%$ & $60 \%$ & $90 \%$ \\
9 & G2 & $20 \%$ & $60 \%$ & $90 \%$ \\
10 & G2 & $40 \%$ & $90 \%$ & $97 \%$ \\
11 & G2 & $30 \%$ & $80 \%$ & $97 \%$ \\
12 & G2 & $20 \%$ & $80 \%$ & $97 \%$ \\
13 & G3 & $50 \%$ & $85 \%$ & $80 \%$ \\
14 & G3 & $10 \%$ & $60 \%$ & $100 \%$ \\
15 & G3 & $80 \%$ & $100 \% *$ & $100 \%$ \\
16 & G3 & $60 \%$ & $85 \%$ & $90 \%$ \\
17 & G3 & $70 \%$ & $80 \%$ & $80 \%$ \\
18 & G3 & $40 \%$ & $80 \%$ & \\
\hline
\end{tabular}

* calo ósseo proeminente.

G1: esponja de colágeno e solução salina $0,9 \%$; G2: esponja de colágeno e medula óssea processada; G3: esponja de colágeno, medula óssea processada e rhBMP-2.

Tabela 3. Resultados do teste t na comparação do crescimento ósseo segundo os grupos, aos 15,30 e 45 dias

\begin{tabular}{lccc}
\hline Grupos & 15 dias & 30 dias & 45 dias \\
\hline G1 e G2 & 0,955 & 1,963 & 3,019 \\
G1 e G3 & 2,433 & 2,548 & 2,545 \\
G2 e G3 & 2,203 & 0,652 & 0,307 \\
\hline
\end{tabular}

G1: esponja de colágeno e solução salina $0,9 \%$; G2: esponja de colágeno e medula óssea processada; G3: esponja de colágeno, medula óssea processada e rhBMP-2.

Neste experimento, pôde ser observado que os cães do grupo que recebeu células-tronco e rhBMP-2 apresentaram melhor porcentual de cicatrização em todos os tempos avaliados, semelhante aos resultados de Ferrigno et al. (2007). Lima et al. (2004), ao utilizarem rhBMP-2 em fraturas diafisárias instáveis do rádio de coelhos, observaram que, em relação ao grupo-controle, pela densitometria óptica radiográfica, não há diferença entre os membros tratados ou não com esse biomaterial. Essa diferença ocorre somente pelo exame radiográfico aos 30 dias de pós-operatório, com maior porcentagem de restabelecimento cortical.

O carreador escolhido foi a esponja de colágeno, que, embora não apresente todas as características de um scaffold ideal (Potier e Petite, 2005), mostrou-se maleável, biocompatível, poroso, radiotransparente e reabsorvível. Além disso, quando colocado no botão celular, esse carreador, por ser uma esponja, embebe-se com a fração de CTM, mantendo-a no local desejado por mais tempo, uma vez que o tempo de absorção desse material é em torno de 14 dias. Pode-se, então, considerar que esse carreador se mostrou apropriado para o objetivo esperado.

\section{CONCLUSÕES}

Células-tronco mesenquimais aplicadas isoladamente ou associadas à rhBMP-2 induzem à cicatrização óssea mais rápida da tíbia em defeitos experimentais de cães. Nanocristais Q-tracker são eficientes marcadores para identificação de célulastronco mononucleares adultas quando aplicados em defeito ósseo de cão. 


\section{AGRADECIMENTOS}

Ao Conselho Nacional de Desenvolvimento Científico e Tecnológico (CNPq), pelo financiamento da pesquisa vinculada ao processo 302710/2005-1. Às empresas: Pedigree, Pharmacia Brasil Ltda., Ouro Fino e JP Indústria Farmacêutica S.A., pela doação de material que contribuiu para a realização deste trabalho.

\section{REFERÊNCIAS BIBLIOGRÁFICAS}

AZZAZY, H.M.E.; MANSOUR, M.M.H.; LUONG, Q. et al. Nanodiagnostics: A new frontier for clinical laboratory medicine. Clin. Chem., v.52, p.1238-1246, 2006.

BOYUM, A. Separation of leukocytes from blood and bone marrow. Scand. J. Clin. Lab. Invest., v.21, p.77-79, 1968 .

CHU, T.M.G.; WARDEN, S.J.; TURNER, C.H. et al. Segmental bone regeneration using a loadbearing biodegradable carrier of bone morphogenetic protein-2. Biomaterials, v.28, p.459-467, 2007.

DOUAT, E.S.V. Estudo comparativo do efeito do ultrassomterapêutico de $1 \mathrm{MHZ}$ com frequência de repetição de pulso de $100 \mathrm{MHZ}$ e $16 \mathrm{HZ}$ no reparo de osteotomia por escareação em tíbia de rato. 2004. 74f. Dissertação (Mestrado) - Escola de Engenharia de São Carlos, Universidade de São Paulo, São Carlos, SP.

FERRIGNO, C.R.A.; NINA, M.I.D.; FANTONI, D.T. et al. Estudo comparativo entre as osteossínteses com placas e osteossínteses com placas associadas a enxertos de proteína morfogenética óssea (Gen-Tech) em fraturas distais de rádio-ulna em cães com menos de seis quilos. Pesq. Vet. Bras., v.27, p.65-69, 2007.

GARON, E.B; MARCU, L.; LUONG, Q. et al. Quantum dot labeling and tracking of human leukemic, bone marrow and cord blood cells. Leukemia Res., v.31, p.643-651, 2007.

GONÇALVES, E.A.L.; GUIMARÃES, S.A.C. Proteínas morfogenéticas ósseas: terapêutica molecular no processo de reparo tecidual. Rev. Odontol. Univ. São Paulo, v.12, p.299-304, 1998.

KIRSCHSTEIN, R. Stem cells: Scientific Progress and Future Research Directions [online].
Department of Health and Human Services. June 2001. Disponível em: <http://stemcells.nih.gov/info/scireport/2001report> . Acessado em 10 jun. 2007.

KRAUS, K.H.; KIRKER-HEAD, C. Mesenchymal stem cells and bone regeneration. Vet. Surg., v.32, p.232-242, 2006.

LIMA, A.F.M.; RAHAL, S.C.; VOLPI, R.S. et al. Aspectos radiográficos e densitométricos na consolidação de fraturas tratadas por proteínas morfogenéticas ósseas em rádio de coelhos. Braz. J. Vet. Res. Anim. Sci., v.41, p.416-422, 2004.

LUCARELLI, E.; DONATI, D.; CENAECHI, A. et al. Bone reconstruction of large defects using bone marrow derived autologous stem cells. Transf. Apher. Sci., v.30, p.169-174, 2004.

PIZZO, P.A.; POPLACK, D.G. Principles and practice of pediatric oncology. Filadelfia: Lippincott Williams \& Wilkins, 2005. 1780p.

POTIER, E.; PETITE, H. Utilisation thérapeutique des cellules souches en orthopédie. Pathol. Biol., v.53, p.142-148, 2005.

PRADO, F.A.; ANBINDER, A.L.; JAIME, A.P.G. et al. Defeitos ósseos em tíbias de ratos: padronização do modelo experimental. Rev. Odont. UNICID, v.18, p.7-13, 2006.

ROOSTAEIAN, J.; CARLSEN, B.; SIMHAEI, D. et al. Characterization of Growth and Osteogenic Differentiation of Rabbit Bone Marrow Stromal Cells. J. Surg. Res., v.133, p.76-83, 2006.

SARKAR, M.R.; AUGAT, P.; SHEFELBINE, S.J. et al. Bone formation in a long bone defect model using a platelet-rich plasma-loaded collagen scaffold. Biomaterials, v.27, p.1817-1823, 2006.

SILVEIRA, C.D.; VIEIRA, S.; SOUZA, F.S.L. et al. Stem cell therapy for cardiology: a new path to humanity and a new care for nurses - a case report. Online Braz. J. Nurs. [online] 2005 Apr, v.4. Disponível em: www.uff.br/nepae/objn401silveiraetal.htm. Acessado em: 21 mai. 2006.

SINGHATANADGIT, W.; SALIH, W.; OLSEN, I. Shedding of a soluble form of BMP receptor-IB controls bone cell responses to BMP. Bone, v.39, p.1008-1017, 2006. 